\title{
${ }^{\angle B O N E \& / O / 7}$ Rang retractors for sciatic notch exposure during pelvic osteotomy
}

S. Thomas,

T. Theologis,

A. M. Wainwright

From the Nuffield

Orthopaedic Centre, Oxford, England

S. Thomas, MA, MRCS,

Specialist Registrar

T. Theologis, FRCS,

Consultant Orthopaedic

Surgeon

A. M. Wainwright,

FRCS(Orth), Consultant

Orthopaedic Surgeon

Nuffield Orthopaedic Centre,

Windmill Road, Headington,

Oxford, UK.

Correspondence should be sent to Mr A. M. Wainwright at 30 Orchard Close, Oxfordshire OX9 3JR, UK; email: andy.wainwright @noc.anglox.nhs.uk

(C)2005 British Editorial Society of Bone and Joint Surgery doi:10.1302/0301-620X.87B3. $15810 \$ 2.00$

$J$ Bone Joint Surg [Br] 2005;87-B:408-9.

Received 12 July 2004;

Accepted after revision

1 October 2004

We present simple but effective retractors used in pairs to expose the sciatic notch during Salter innominate osteotomy. We have found them to be useful for a wide range of procedures requiring similar exposure. We present them here in tribute to the memory of the designer Mercer Rang.

During his later years Mercer Rang designed a set of retractors for the safe exposure of the sciatic notch during pelvic osteotomy. Procedures involving bone cuts around the sciatic notch are technically challenging. The passage of a saw around the notch is difficult and endangers the sciatic nerve and gluteal vessels. Rang's retractors (Jantek Engineering, Ontario, Canada) were advocated by Tachdjian ${ }^{1}$ for the Salter innominate osteotomy but have not been formally reported. We have also used them to expose the proximal and distal femur for rotational osteotomy. They are similarly useful in adolescent and adult orthopaedics to facilitate safe bone section in the course of medial displacement Chiari $^{2}$ or triple osteotomy ${ }^{3}$ and may help in the passage of cerclage wires around the adult femoral shaft.

The retractors were originally designed by Mercer Rang with Jan Koreska, an engineer who worked with him at The Sick Children's Hospital, Toronto. They have since been modified and produced in different sizes by John Wedge, staff surgeon at the same institution. They are chevron-shaped levers whose gutters interlock by means of differentially-sized, triangular spade tips (Fig. 1). Once engaged either side of the sciatic notch they provide circumferential protection of the soft tissues and a generous space within which to pass and manipulate a Gigli saw (Fig. 2).

Operative technique. The innominate osteotomy is indicated for acetabular dysplasia in the younger child with developmental dysplasia or dislocation of the femoral head. It is designed to rotate the intact acetabulum as a unit, hinging about the mobile pubic symphysis, in order to redirect it over its anterosuperior deficiency. A concentrically reduced hip with free range of movement is an absolute pre-requisite. It was devised and described by Salter ${ }^{4}$ in 1961 with good results. ${ }^{5,6}$

The bone cut is made in a transverse direction, most easily with a Gigli saw, from the greater sciatic notch to just above the anterior inferior iliac spine. Technical refinements have been reported ${ }^{7}$ including the use of simple lever retractors rotated through $90^{\circ}$ in order to maintain sufficient space around the deep aspect of the notch. This method, however, offers little protection to the soft tissues while the saw is moved back and forth. We use a modified Smith-Peterson anterior approach to the acetabulum ${ }^{8}$ through an oblique bikini skin incision below the iliac crest. The iliac apophysis is split and the dissection carried down subperiosteally to the sciatic notch, using Cobb elevators, with a swab to control bleeding and increase the interval between the periosteum and the notch. With the notch exposed within the subperiosteal plane, flat Hohmann retractors are replaced with the Rang retractors. A secure mechanical interlock between the tips is confirmed prior to passing the Gigli saw. This is achieved by first passing a curved Moynihan cholecystectomy clamp under direct vision. The deep gutter maintained between the tips of the retractors facilitates this. The Gigli saw tip is then grasped and pulled back through the notch in the clamp. Gentle leverage on the tubular retractor handles creates a clear transverse plane in which to make the saw cut. The soft tissues are protected on all sides from the barbed saw which lies within the gutter of each arm of the retractor.

\section{Discussion}

We have been using these retractors routinely in our unit since the beginning of 2002 and have encountered no complications from their 


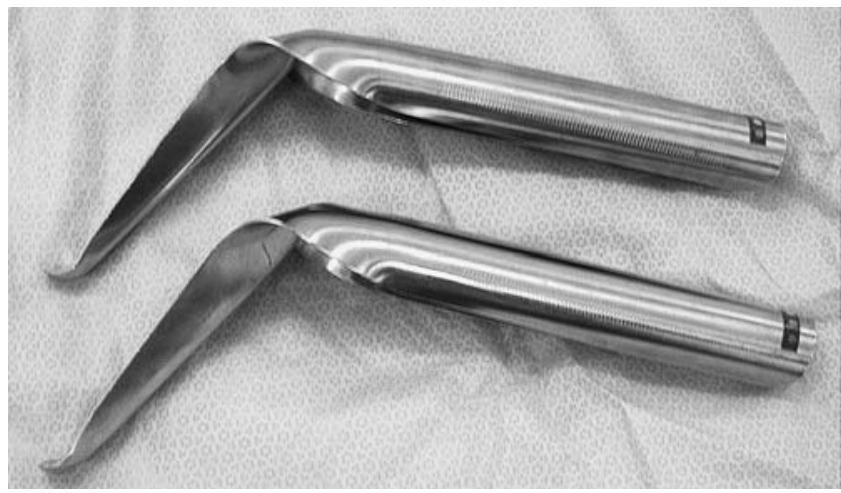

Fig. 1a

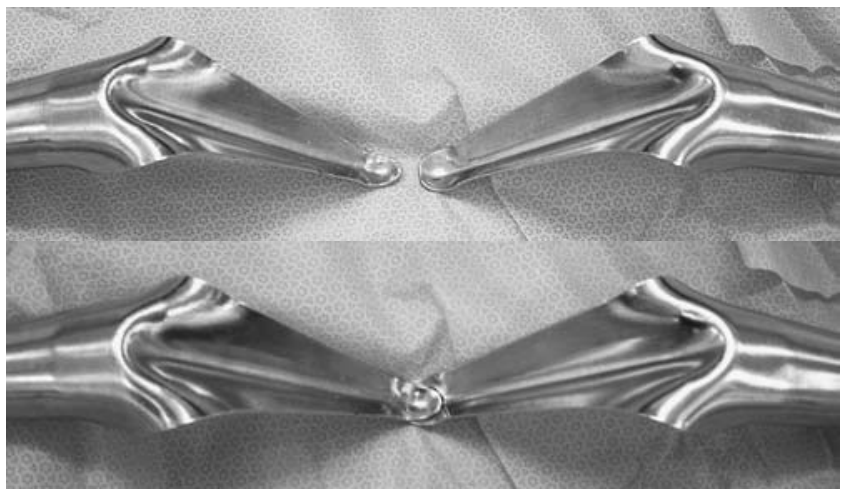

Fig. 1b

Photographs of Rang retractors viewed from a) the side and b) above.
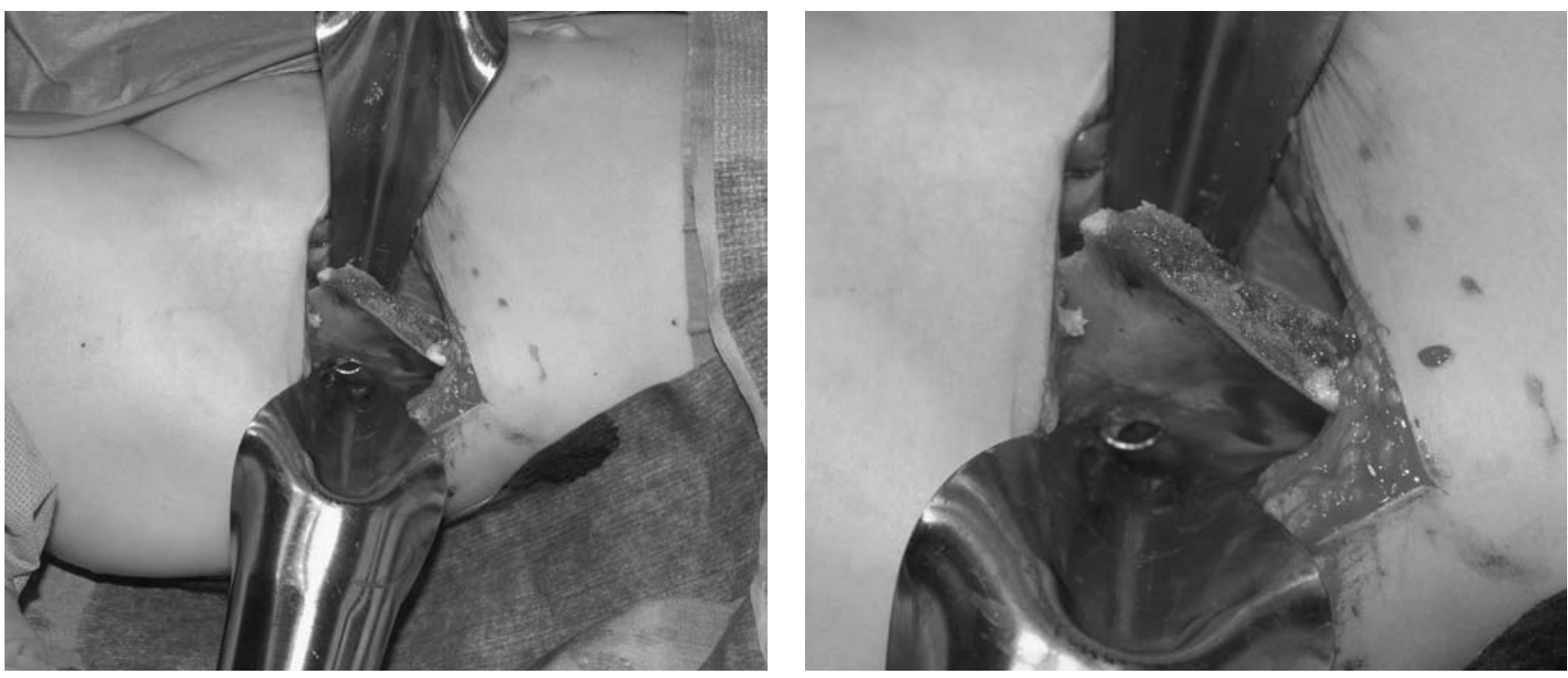

Fig. 2

Photographs of Rang retractors in place during innominate osteotomy.

use. The steps of saw passage and soft-tissue protection are made both easier and safer for osteotomies around the pelvis and proximal femur in both paediatric and adult cases. We recommend their use to the wider orthopaedic community.

We are grateful to Benjamin Alman for providing historical information for this report.

No benefits in any form have been received or will be received from any commercial party related directly or indirectly to the subject of this article.

\section{References}

1. Tachdjian MO. Osteotomies around the hip joint. In: Atlas of paediatric orthopaedic surgery. Philadelphia: W.B. Saunders Co, 1994:368-606.
2. Chiari VK. Beckenosteotomie zur Pfannendachplastik. Wiener Medizinische Wochenschrift 1953;103:707-13 (in German).

3. Steel HH. Triple osteotomy of the innominate bone. J Bone Joint Surg [Am] 1973, 55-A:343-50.

4. Salter RB. Innominate osteotomy in the treatment of congenital dislocation and subluxation of the hip. J Bone Joint Surg [Br] 1961;43-B:518-39.

5. Salter RB, Dubos JP. The first fifteen years personal experience with innominate osteotomy in the treatment of congenital dislocation and subluxation of the hip. Clin Orthop 1974;98:72-103.

6. Bohm P, Brzuske A. Salter innominate osteotomy for the treatment of developmental dysplasia of the hip in children: results of seventy-three consecutive osteotomies after twenty-six to thirty-five years of follow-up. J Bone Joint Surg [Am] 2002;84-A:178-86.

7. Macnicol M, Al Ramashdeh H, Auld J. Technical aspects of the Salter innominate osteotomy. Curr Orthop 2000;14:209-14.

8. Smith-Peterson MN. Approach to and exposure of the hip joint for mould arthroplasty. J Bone Joint Surg [Am]1949;31-A:400. 